\title{
Preparation and properties of 3D interconnected CNTs/Cu composites
}

https://doi.org/10.1515/ntrev-2020-0013

Received Nov 13, 2019; accepted Dec 06, 2019

Abstract: In this paper, the 3D pore structure of $\mathrm{CuCr}$ powders were obtained by pre-press shaping process, and finally the 3D interconnected carbon nanotubes/copper (CNTs/Cu) composites with excellent properties were insitu synthesized by chemical vapor deposition (CVD) and spark plasma sintering (SPS) technique. The morphology and structure of $\mathrm{CNTs} / \mathrm{Cu}$ composites are characterized by scanning electron microscopy (SEM), Raman spectra, transmission electron microscopy (TEM), X-ray diffraction (XRD) and X-ray photoelectron spectroscopy (XPS), and the results showed that the quality of CNTs and the interfacial bonding strength of CNTs/Cu composites can be improved owing to the 3D pore structure. Meanwhile, the 3D pore structure was favorable to avoid pollution of CNTs during the synthesis process. The tensile strength of CNTs/Cu composites increased to $421.2 \mathrm{MPa}$, with $47.6 \%$ enhancements compared to CuCr. Furthermore, the coefficient of friction (COF) reduced to 0.22 and the corrosion resistance were increased by $51.86 \%$ compared to $\mathrm{CuCr}$. Consequently, our research provides a novel and an effective method for the synthesis of high quality CNTs/Cu composites.

Keywords: chemical vapor deposition, 3D interconnected carbon nanotubes/copper composites, preparation, properties

\footnotetext{
*Corresponding Author: Xujun Mi: State Key laboratory of Nonfer rous Metals and Processes, GRINM Group Co., Ltd, Beijing 100088, China; GRIMAT Engineering Institute Co., Ltd., Beijing 101407, China; General Research Institute for Nonferrous Metals, Beijing 100088, China; Email: mixujun006@163.com

*Corresponding Author: Ping Liu: School of Materials Science and Engineering, University of Shanghai for Science and Technology, Shanghai 200093, China; Email: lpusst@163.com *Corresponding Author: Yi Zhang: School of Materials Science and Engineering, Henan university of science and technology, Luoyang, 471023, China; Email: zhangyiuss@163.com Shaohua Chen: State Key laboratory of Nonferrous Metals and Processes, GRINM Group Co., Ltd, Beijing 100088, China; GRIMAT Engineering Institute Co., Ltd., Beijing 101407, China; General
}

\section{Introduction}

CNTs/Cu composites have attracted increasing attention in the aerospace and ground transportation because of their excellent properties in many aspects, such as super mechanical strength and high electrical conductivity [1-3]. The key techniques of the synthesized CNTs/Cu composites mainly include the uniform dispersion of CNTs in the $\mathrm{Cu}$ matrix and good interfacial bonding, which can exert the full potential of CNTs as a reinforcement in the $\mathrm{Cu}$ matrix [4-7]. The existing reports for the $\mathrm{CNTs} / \mathrm{Cu}$ composites focused mainly on electrochemical deposition [8], powder metallurgy [9], fusion casting [10] and stirring casting [11]. Walid et al. [12] investigated the mechanical properties of CNTs/Cu composites prepared by electroless deposition and spark plasma sintering (SPS), and the electrical conductivity reached 72\%IACS, the Vickers hardness achieved $108 \mathrm{HV}$, as well as 341.2 MPa for yield strength. Shukla et al. [13] investigated the tensile strength of CNTs/Cu composites prepared via mechanical alloying and hot pressing sintering, the results showed that the tensile strength of CNTs/Cu composites reached $330 \mathrm{MPa}$. However, the above-stated method cannot be achieved the uniform dispersion of CNTs in the $\mathrm{Cu}$ matrix and the good interfacial bonding between the $\mathrm{CNTs}$ and $\mathrm{Cu}$, which will result in the failure of realization of CNTs as a reinforcement [14-16]. Therefore, it is necessary to investigate a novel method to disperse CNTs uniformly in the Cu matrix, and to improve the interfacial bonding between CNTs and $\mathrm{Cu}$ matrix.

Research Institute for Nonferrous Metals, Beijing 100088, China; Aluminum Corporation of China Co., Ltd., Beijing 100082, China Shaoli Fu, Xiaohong Chen: School of Materials Science and Engineering, University of Shanghai for Science and Technology, Shanghai 200093, China

Shaohua Chen and Shaoli Fu are co-first authors

Dong Liang: State Key laboratory of Nonferrous Metals and Processes, GRINM Group Co., Ltd, Beijing 100088, China; GRIMAT Engineering Institute Co., Ltd., Beijing 101407, China; General Research Institute for Nonferrous Metals, Beijing 100088, China David Hui: Department of Mechanical Engineering, University of New Orleans, New Orleans, LA 70148, United States of America 
In this paper, a new idea of combining precompression with CVD to achieve the in-situ grown CNTs in the voids of pre-compressed 3D interpenetrating $\mathrm{CuCr}$ alloy powders to form 3D interconnected CNTs/Cu composited was first proposed and realized. The method firstly pre-compacted $\mathrm{CuCr}$ alloy powders at a pressure of 50 $\mathrm{MPa}$ at room temperature to form the $\mathrm{CuCr}$ pre-compacted bulk with 3D pore structure, and secondly synthesized CNTs on the CuCr pre-compacted bulk by CVD, and finally formed CNTs/Cu composites by SPS [17]. The method of pre-compacting into bulk materials not only avoids the instability of the atmosphere in the process of directly synthesizing CNTs and uneven dispersion of CNTs as well as the problem of easy-contaminated, but also significantly improves the interfacial bonding of the composites. In addition, CVD avoids the structural damage and contamination of CNTs under the high-energy and high-temperature generated by the conventional external addition method, and achieves the uniform dispersion and in-situ growth of the CNTs in the copper matrix [18-20]. The combination of the pre-compacting and CVD provides excellent 3D interconnected CNTs/Cu composites, which provides a new and effective way for the preparation of high performance copper-based composites.

\section{Experiment}

\subsection{Preparation of 3D interconnected CNTs/Cu pre-compressed bulk}

Firstly, 15g CuCr (200 mesh, Shanghai Sinopharm Chemical Reagent Co., Ltd, $0.6 \mathrm{wt} \% \mathrm{Cr}$ ) alloy powders were taken a tube furnace for solution-aging treatment to achieve the homogeneous precipitation of catalyst $\mathrm{Cr}$ particles. Then the $\mathrm{CuCr}$ alloy powders were pre-compacted at room temperature, and the pressure was 50MPa. Then a $\mathrm{CuCr}$ precompressed bulk was formed, which had 3D void structure of $30 \mathrm{~mm}$ in diameter and $3 \mathrm{~mm}$ in height. Then CNTs/Cu pre-compacted bulk was obtained at $800^{\circ} \mathrm{C}$ for $60 \mathrm{~min}$.

\subsection{Preparation of 3D interconnected CNTs/Cu composites}

The 3D interconnected CNTs/Cu pre-compacted bulk was loaded into a graphite mold (inner diameter $\varnothing 30 \mathrm{~mm}$ ) and sintered in a spark plasma sintering furnace to get the $3 \mathrm{D}$ interconnected CNTs/Cu composites. The heating rate was $100^{\circ} \mathrm{C} / \mathrm{min}$, the sintering pressure was $30 \mathrm{MPa}$, the sinter- ing temperature was $900^{\circ} \mathrm{C}$, and the sintering time was $10 \mathrm{~min}$. The experimental process is shown in Figure 1. Finally, the composites were hot rolled $\left(850^{\circ} \mathrm{C}, 60 \%\right.$ deformation) to increase its relative density.

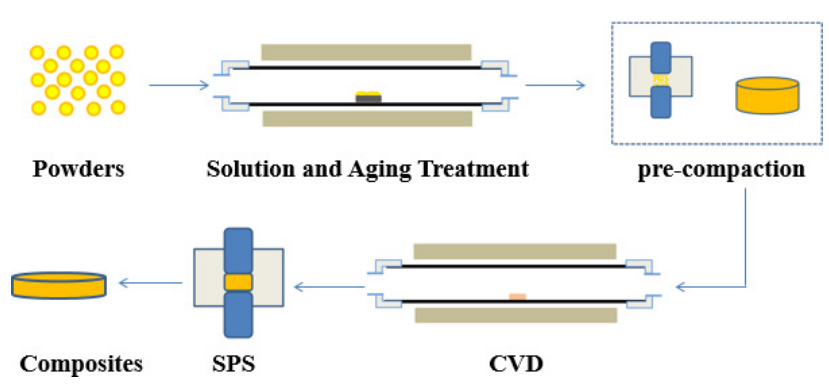

Figure 1: Schematic illustration of the preparation process of 3D interconnected CNTs/Cu composites

\subsection{Characterization}

The morphology of the materials was characterized by scanning electron microscopy (SEM, QUANTA FEG 450). The graphite-amorphous carbon features of CNTs in the composites were characterized by Raman spectroscopy (Raman Station 400F) with a wavelength of $532 \mathrm{~nm}$. Elemental composition and chemical bonds were characterized by X-ray photoelectron spectroscopy (Thermo ESCALAB 250). The tensile strength, hardness and electrical conductivity of the composites were tested using a Zwick precision line vario, a microhardness tester (HX-1000TM/LCD) and a digital metal conductivity tester (D60K). The density of the composites was measured by the Archimedes drainage method. The corrosion resistance and tribological properties of the composites were investigated using a friction wear machine (HIIT-2II) and an electrochemical workstation (CHI 660D, CHI 1140C), respectively.

\section{Results and discussion}

\subsection{Microstructural characterization of the 3D interconnected CNTs/Cu composites}

Figure 2 shows the surface and internal morphology of the 3D CNTs/Cu bulk materials. Figure $2 \mathrm{a}$ and the inset $\mathrm{a}_{1}$ show that the number of CNTs on the surface of the 3D pore structure is small. The average outer diameter of the CNTs is 20-40 nm, the length is about $1400 \mathrm{~nm}$. But the distribu- 

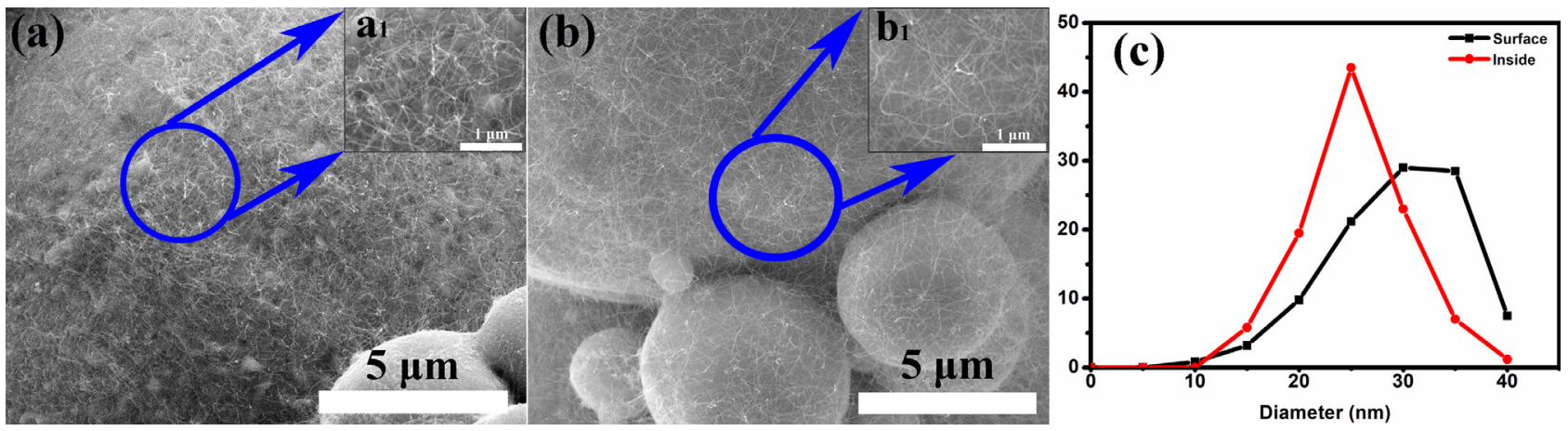

Figure 2: (a) SEM image of the 3D CNTs/Cu surface morphology (b) SEM image of the 3D CNTs/Cu internal morphology (c) Percentage of CNTs of different diameters

tion is uneven, and there are more defects. The reasons are that $\mathrm{C}_{2} \mathrm{H}_{4}$ and $\mathrm{H}_{2}$ flow through the surface of the substrate directly and quickly, leading to the CVD reaction incompletely and formation of impurities such as amorphous carbon easily. What's worse, it is more susceptible to be contaminated due to a large exposed surface area. From Figure $2 b$ and the inset $b_{1}$, we can see that the CNTs are evenly distributed in the bulk. In addition, the walls of CNTs are clean, and there are no defects and amorphous carbon. The average outer diameter of the CNTs is 20-30 $\mathrm{nm}$ and the length is increased to about $1800 \mathrm{~nm}$. This is because the gas flow in the 3D porous structure is relatively stable, and the reaction is relatively sufficient. Furthermore, the interior is not easily contaminated, so the matrix is clean. The average gap of the adjacent copper powder in the pre-compressed bulk is $712 \mathrm{~nm}$, that is, the porosity is $71.81 \%$. But the porosity of the pre-compressed bulk reduced to $66.43 \%$ after the in-situ synthesis of CNTs. The CNTs connected to the matrix to realize the cross-link of $\mathrm{Cu}$ and CNTs as well as CNTs and CNTs. At the same time, the pre-compression form will have a copper-copper connection, so the three kinds of connections are evenly distributed to form a 3D interconnected network structure.

Figure 3 shows the Raman spectrum of the surface and interior of 3D interconnected CNTs/Cu composites. The synthesis environment of surface CNTs is similar to the direct synthesis one. The peak ratio $\left(\mathrm{I}_{D} / \mathrm{I}_{G}\right)$ of the $D$ peak near $1347.39 \mathrm{~cm}^{-1}$ and the $\mathrm{G}$ peak near $1593.01 \mathrm{~cm}^{-1}$ is 1.017 , indicating the CNTs having more amorphous structures and defects. But for the internal materials, due to the existence of 3D pores, the synthesis environment of CNTs is relatively stable, and the peak ratio $\left(\mathrm{I}_{D} / \mathrm{I}_{G}\right)$ of the generated CNTs is significantly reduced to 0.941 . The defects density of CNTs is reduced and the degree of graphitization is enhanced [21-24]. It indicates that pre-compacted to the 3D porous structure to grow carbon nanotubes can effectively

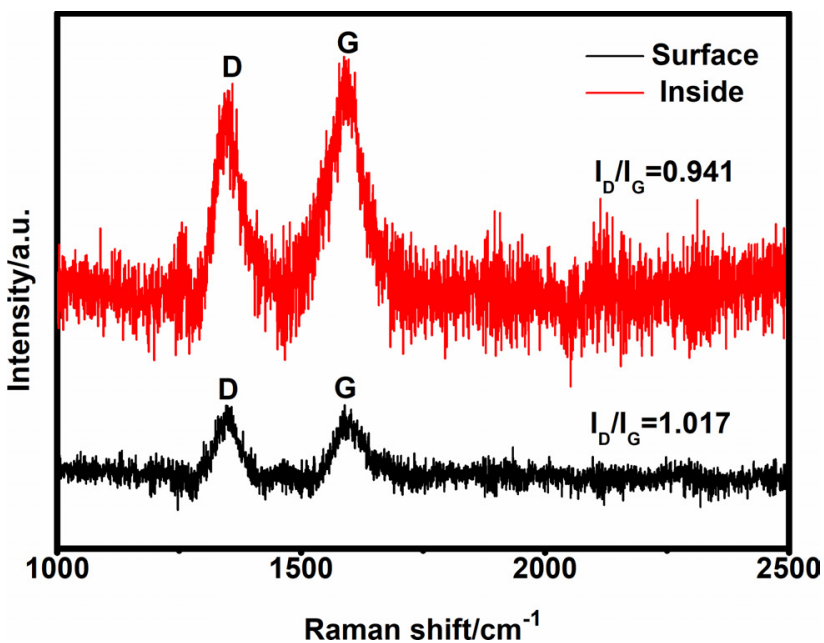

Figure 3: Raman spectrum of surface and interior of CNTs/Cu composites

suppress the formation of amorphous carbon, thereby improving the purity of CNTs.

In order to study the microstructure of 3D CNTs/Cu composites, XRD and XPS tests were performed. Figure 4a shows the XRD pattern of the 3D CNTs/Cu composites and $\mathrm{CuCr}$. The composites exhibited only three characteristic peaks corresponding to $\mathrm{Cu}$ (PDF No. 851, 326), and showed no peaks of CNTs and Cr. The possible reason is that the strong diffraction peaks of Cu covered the signals of CNTs and $\mathrm{Cr}$. Except for the copper peak, no other peaks were found, indicating the good chemical stability between copper matrix and carbon nanotubes [20].

XPS test was performed to study the chemical composition and oxidation state of the 3D interconnected $\mathrm{CNTs} / \mathrm{Cu}$ composites. Figure $4 \mathrm{~b}$ shows the main elemental composition and the content of two samples. Figure 4c shows the XPS core level Cu2p spectrum of two composite powders with two $\mathrm{Cu}$ peaks with binding energies of 952.3 $\mathrm{eV}$ and $932.6 \mathrm{eV}$, respectively, corresponding to $\mathrm{Cu} 2 \mathrm{p}_{1 / 2}$ 

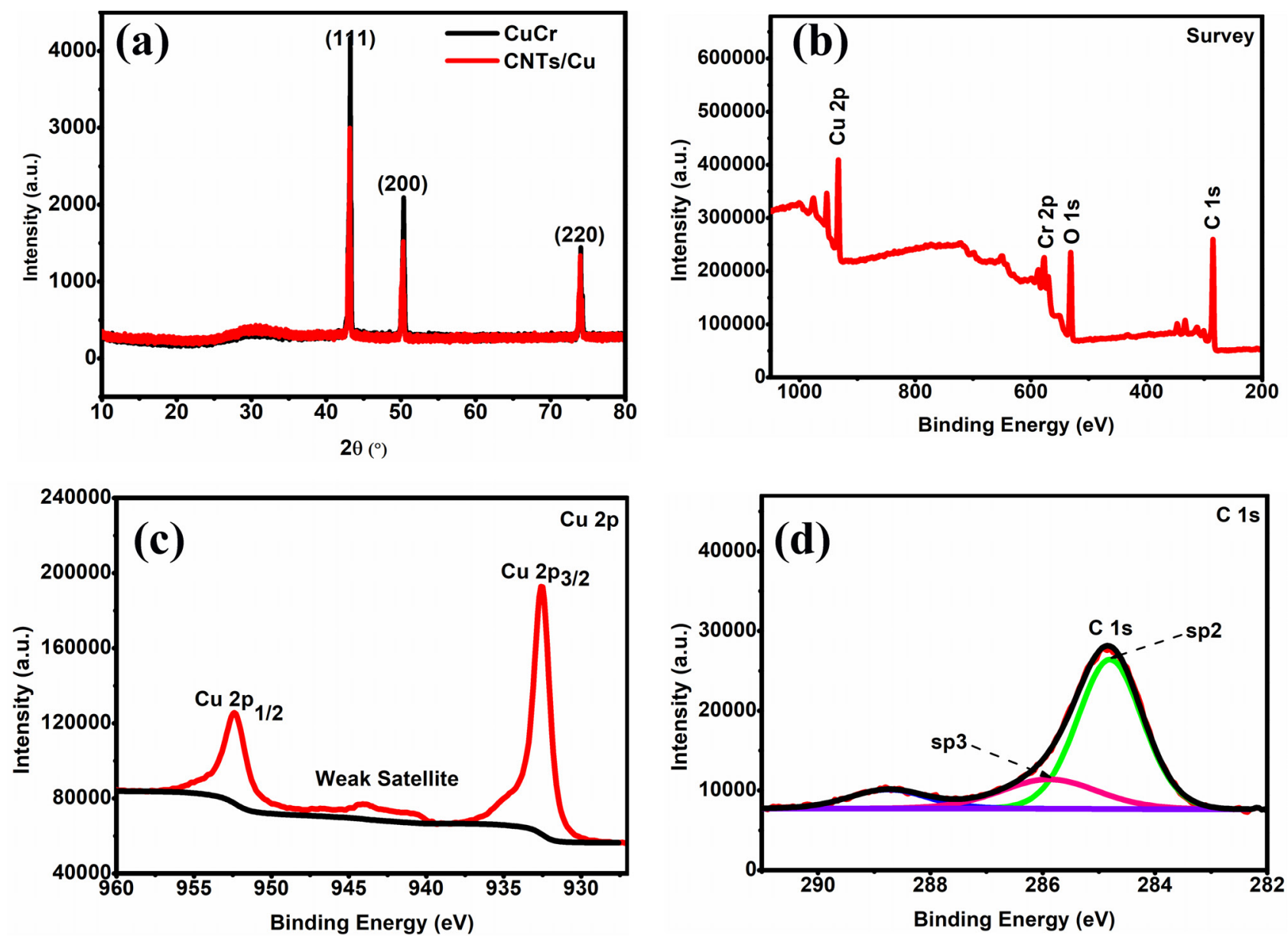

Figure 4: (a) XRD patterns of the 3D interconnected CNTs/Cu composites and $\mathrm{CuCr}$ (b) XPS wide scan of the 3D interconnected CNTs/Cu composites and $\mathrm{CuCr}$ (c) Cu 2p XPS map of the 3D interconnected CNTs/Cu composites (d) C 1s XPS map of the 3D interconnected CNTs/Cu composites

and $\mathrm{Cu} 2 \mathrm{p}_{3 / 2}$ [25]. There are also satellite peaks in the $\mathrm{Cu} 2 \mathrm{p}$ spectrum, declaring that the presence of a small amount of $\mathrm{CuO}$ in the composites due to surface exposure of the 3D surface structure leading to slight oxidation of the copper matrix [26]. Figure $4 \mathrm{~d}$ shows the $\mathrm{C} 1 \mathrm{~s}$ spectrum of the sample. In order to study the structure of the CNTs, the fitted peaks in the linear are attributed to sp2 hybridization and sp3 hybridized carbon, respectively [27]. It is clear that the percentage of sp2 hybrid carbon sample is higher, which means it has a higher degree of graphitization and fewer CNTs lattice defects [28]. This confirms that pre-compressing the alloy powders into a 3D loose and porous structure firstly, and then in-situ growing carbon nanotubes to form a 3D interconnected composites is beneficial to the growth of CNTs and contributes to the improving the properties of the materials.

The interfacial bonding between carbon nanotubes and copper matrix and the one between copper and copper have a significant effect on the properties of compos- ites. HRTEM was used to study the interfacial bonding of the 3D interconnected CNTs/Cu composites. Figure 5 is the TEM images of the interface for 3D interconnected CNTs/Cu composites. Figure 5a shows that the CNTs are uniformly dispersed in the $\mathrm{Cu}$ matrix and the CNTs are not aggregated and the tube walls are clean. Figure $5 \mathrm{~b}$ is a high-magnification TEM image of the interface between CNTs and $\mathrm{Cu}$. The CNTs are tightly bound to the $\mathrm{Cu}$ matrix, with no obvious physical gaps and no intermediate compounds [29-31]. This result indicates that the good interfacial bonding between CNTs and $\mathrm{Cu}$ are well retained in the 3D interconnected structure. At the same time, the interface between copper and copper is very good, and a large amount of mutual diffusion occurs among the copper atoms, the atomic level bonding is achieved at the interface. The combination of the interface greatly improves the strength of the matrix, and eliminates the disadvantage of the weak interfacial bonding between copper and copper as well as the unrealizable atomic level bonding prepared 

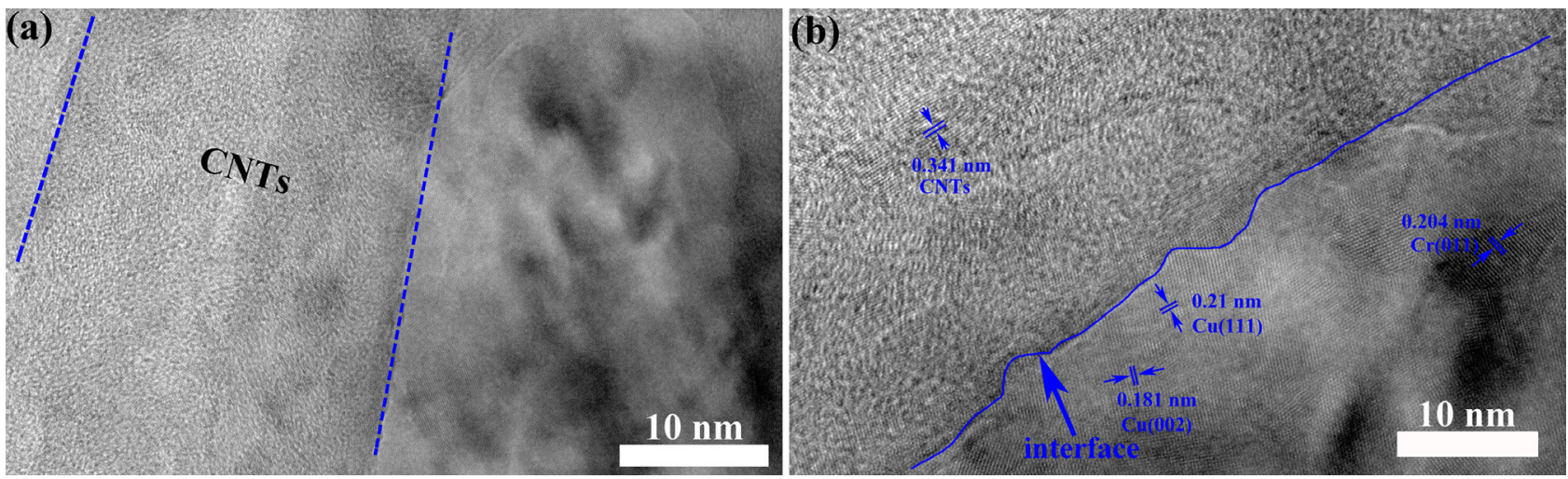

Figure 5: (a) TEM topography of 3D interconnected CNTs/Cu composites (b) HRTEM morphology of the 3D interconnected CNTs/Cu composites

Table 1: Properties of the 3D interconnected CNTs/Cu composites and $\mathrm{CuCr}$

\begin{tabular}{cccccc}
\hline Sample & $\begin{array}{c}\text { Tensile Strength } \\
(\mathrm{MPa})\end{array}$ & $\begin{array}{c}\text { Starin } \\
(\%)\end{array}$ & $\begin{array}{c}\text { Vickers Hardness } \\
(\mathrm{HV})\end{array}$ & Relative density (\%) & Conductiviy (\%IACS) \\
\hline $\mathrm{CuCr}$ & 285.4 & 21.7 & 122.2 & 99.2 & 85.7 \\
$\mathrm{CNTs} / \mathrm{Cu}$ & 421.2 & 17.9 & 130.2 & 98.9 & 84.6 \\
\hline
\end{tabular}

by the conventional method, thereby the tensile strength of the composites is improved.

\subsection{Performance of the 3D interconnected CNTs/Cu composites}

Figure 6 shows the tensile stress-strain curve after rolling of the 3D interconnected CNTs/Cu composites. For comparison, the tensile stress-strain curve of $\mathrm{CuCr}$ was also tested. The yield strength, elongation, hardness and relative density are summarized in Table 1 . The average yield strength of $\mathrm{CuCr}$ is $285.4 \mathrm{MPa}$, and the elongation is about $21.7 \%$, which is plastic fracture. The elongation of the 3D interconnected CNTs/Cu composites decreased from $21.7 \%$ to 17.9\% compared with $\mathrm{CuCr}$, but its strength and hardness were greatly improved, and the tensile strength was $47.6 \%$ higher than that of $\mathrm{CuCr}$. There are two main reasons for this. One is the in-situ synthesized carbon nanotubes act as the reinforced phase, which further improves the tensile strength and hardness. The other one is that CNTs and CNTs, CNTs and copper, copper and copper are interconnected, forming 3D network structure, which increases the resistance to dislocation motion, and reduces the peeling speed and slows the destruction rate of materials. Meanwhile, the strengthening and toughening effect of carbon nanotubes hinders the extension of cracks [32].

The conductivity of the 3D interconnected CNTs/Cu composites and $\mathrm{CuCr}$ was measured by eddy current

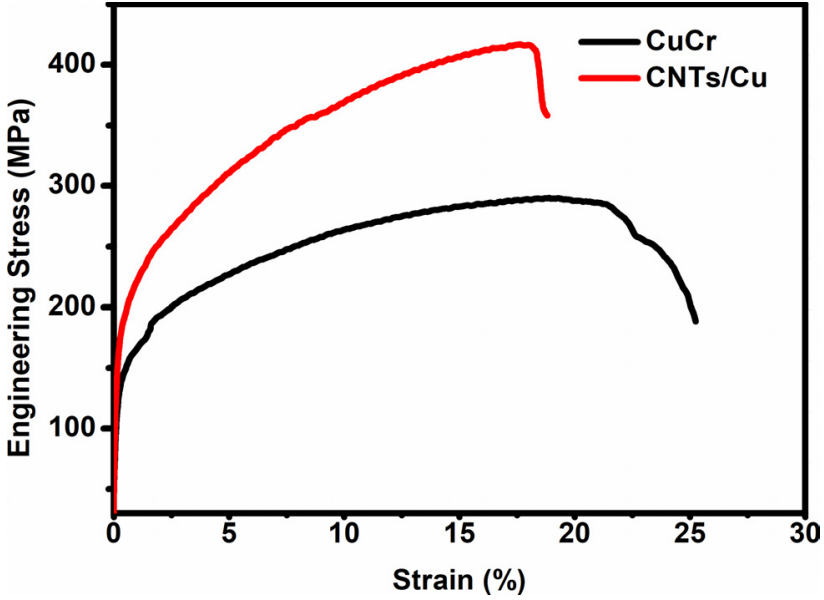

Figure 6: Tensile stress-strain curve of the 3D interconnected CNTs/Cu composites and $\mathrm{CuCr}$ after rolling

method. The results are shown in Table 1 . The conductivity of $\mathrm{CNTs} / \mathrm{Cu}(85.7 \%)$ decreased only slightly compared to $\mathrm{CuCr}$ (84.6\% IACS). The slight decrease in conductivity mainly caused by two reasons. First, the mean free path (MFP) of the charge carriers is reduced due to the reduction in matrix particle size and the increase in dislocation density [33]. Second, the voids formed during the sintering process become an insulating barrier for the current [34]. However, the conductivity decreases little and is negligible in this study. The prepared CNTs/Cu composites are still highly conductive materials. This is because the method of 

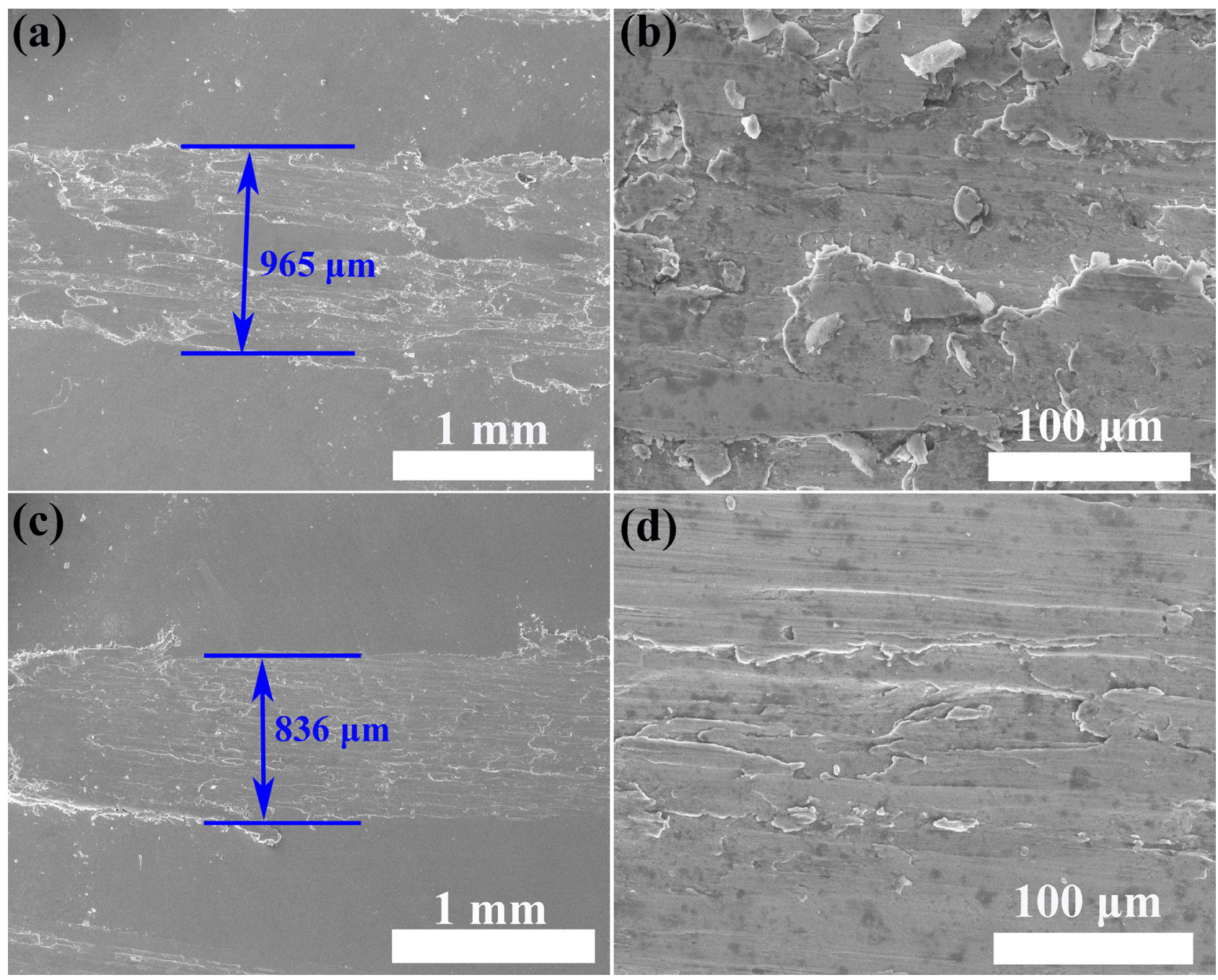

Figure 7: Low-magnification SEM image of friction and wear surface for $\mathrm{CuCr}$ (a) and 3D interconnected CNTs/Cu (c); High-magnification SEM image of friction and wear surface for $\mathrm{CuCr}$ (b) and 3D interconnected CNTs/Cu (d)

Table 2: Friction and wear properties of 3D interconnected CNTs/Cu composites and $\mathrm{CuCr}$

\begin{tabular}{ccc}
\hline Sample & Friction coefficient & Wear loss $(\mathrm{mg})$ \\
\hline $\mathrm{CuCr}$ & 0.51 & 1.9 \\
$\mathrm{CNTs} / \mathrm{Cu}$ & 0.22 & 0.8 \\
\hline
\end{tabular}

pre-pressurizing then growth CNTs is adopted, which can effectively reduce the voids in the final materials and increase the density of the materials. At the same time, the structural features of the interconnected structure and the copper-copper combination are more conducive to current transfer.

Carbon nanotubes are considered to be a new type of solid lubricant in previous studies [35-37]. Figure 7 shows the SEM images of the wear surface for the 3D intercon- nected CNTs/Cu composites and $\mathrm{CuCr}$. The relative friction pair is stainless steel ball. The load is $10 \mathrm{~N}$ and the sliding speed is $0.03 \mathrm{~m} / \mathrm{s}$. The CuCr has a large wear width, and the surface has obvious plastic deformation marks and obvious furrows and sticking pits, and a large piece of debris is peeled off. The wear surface of the 3D interconnected $\mathrm{CNTs} / \mathrm{Cu}$ composites is improved compared with $\mathrm{CuCr}$, and the lamellar cracking phenomenon was greatly reduced. The wear width was reduced from $965 \mu \mathrm{m}$ to $836 \mu \mathrm{m}$, so the wear resistance was significantly improved. The coefficient of friction (COF) and wear of the two materials are summarized in Table 2. The 3D interconnected CNTs/Cu composites exhibited better anti-friction properties (COF $\approx 0.22$ ) compared the COF for $\mathrm{Cu}$ is 0.55 . What's more, the wear loss was reduced from $1.9 \mathrm{mg}$ for $\mathrm{CuCr}$ to $0.8 \mathrm{mg}$ for 3D interconnected CNTs/Cu composites. This is because that the distribution of the CNTs in the 3D interconnected struc- 
ture is more uniform and the material has higher relative density. CNTs plays a self-lubricating role in the matrix during the friction and wear process, some protective films are formed on the worn surface, which reduces the friction coefficient of the composites [38]. At the same time, the interconnected 3D structure hinders the wear and tear of the material during the rubbing process.

Figure 8 is the Tafel curve for 3D interconnected CNTs/Cu composites and $\mathrm{CuCr}$ (the area is $1 \mathrm{~cm}^{2}$ ) in a 3.5 wt $\% \mathrm{NaCl}$ solution. In general, the more positive the selfcorrosion potential and the lower the self-corrosion current density, indicting the better corrosion resistance of the material $[39,40]$. Compared to $\mathrm{CuCr}$, the polarization curve (Ecoor) of the 3D interconnected CNTs/Cu composites exhibits a considerable positive shift, showing better corrosion resistance. The corrosion current density (Icoor) of CNTs/Cu composites is significantly lower than that of $\mathrm{CuCr}$, which indicates that the existence of 3D interconnected structures and the addition of CNTs have a significant effect on slowing down the corrosion process.

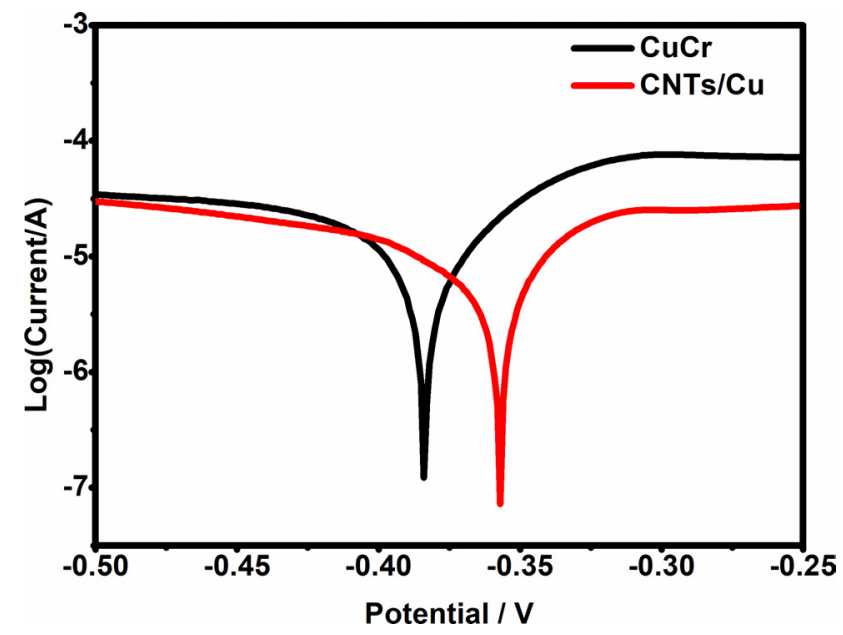

Figure 8: Tafel curve of CNTs/Cu composites and CuCr in 3.5wt.\% $\mathrm{NaCl}$ solution

The protection efficiency (PE) is calculated from the measured Icorr value and equation (1) [41, 42]:

$$
P E=\frac{I_{\text {coor }(\mathrm{Cu})}-I_{\text {coor }(\text { Sample })}}{I_{\operatorname{coor}(\mathrm{Cu})}} \times 100 \%
$$

In addition, the corrosion rate (CR) can be estimated from the corrosion current value according to the standard equation (equation (2)) [43].

$$
C R=\frac{K \times I_{\text {coor }} \times M}{z \times \rho}
$$

In the equation, $\mathrm{z}$ is the valence, equal to $2, \rho$ is the density of materilas, equal to $8.97 \mathrm{~g} / \mathrm{cm}^{3}$, $\mathrm{K}$ is the corrosion rate constant, equal to $3.27 \times 10^{-3} \mathrm{~mm} \cdot \mathrm{g} /(\mu \mathrm{A} \cdot \mathrm{cm} \cdot$ year $), \mathrm{M}$ is the atomic weight, equal to 63.5 .

The electrochemical parameters obtained from the polarization curves are shown in Table 3. It can be seen from the results that the corrosion resistance of $\mathrm{CNTs} / \mathrm{Cu}$ composites is much higher than that of $\mathrm{CuCr}$. This is because the structure of the CNTs/Cu composites is better, and the CNTs is cleaner and more uniformly dispersed in the matrix. This work promoted a corrosion rate reduction of $51.86 \%$, greatly improving corrosion resistance.

Table 3: Corrosion parameters of CNTs/Cu composites and $\mathrm{CuCr}$ in $3.5 \mathrm{wt} . \% \mathrm{NaCl}$ solution

\begin{tabular}{ccccc}
\hline Sample & Ecorr $(\mathrm{V})$ & $\begin{array}{c}\text { Icorr } \\
\left(\mu \mathrm{A} / \mathrm{cm}^{2}\right)\end{array}$ & $\begin{array}{c}\mathrm{CR} \\
(\mathrm{mm} / \text { year })\end{array}$ & PE (\%) \\
\hline $\mathrm{CuCr}$ & -0.39 & 20.99 & 0.243 & - \\
$\mathrm{CNTs} / \mathrm{Cu}$ & -0.36 & 10.13 & 0.117 & $51.86 \%$ \\
\hline
\end{tabular}

\section{Conclusion}

3D interconnected CNTs/Cu composites were prepared by pre-compressing $\mathrm{CuCr}$ alloy powders into 3D pore structure by CVD and SPS. This method provides a stable environment for the growth of carbon nanotubes and improves the quality and distribution of CNTs. At the same time, the 3D interconnected composites prepared by the method exhibits excellent performance in terms of strength and corrosion resistance, and meanwhile the problem of decreased conductivity caused by the addition of carbon nanotubes was solved. Presented work provides a new and an effective way to prepare copper-based composites with excellent mechanical properties and high electrical conductivity.

\section{References}

[1] Ferrer-Anglada N., Gomis V., El-Hachemi Z. et al., Carbon nanotube based composite for electronic applications:CNTconducting polymers, CNT-Cu, Phys. Status. solidi. A, 2006, 203(6), 1082-1087.

[2] Tsai P.C., Jeng Y.R., Experimental and numerical investigation into the effect of carbon nanotube buckling on the reinforcement of CNT/Cu composite, Compos. Sci. Technol., 2013, 79(5), 28-34.

[3] Roy S., Petrova R.S., Mitra S., Effect of carbon nanotube (CNT) functionalization in epoxy-CNT composites, Nanotechnol. Rev., 2018, 7(6), 475-485. 
[4] Cho S., Kikuchi K., Miyazaki T. et al., Multiwalled carbon nanotubes as a contributing reinforcement phase for the improvement of thermal conductivity in copper matrix composite, Scripta. Mater., 2010, 63(4), 375-378.

[5] Liu L., Tang Y., Zhao H. et al., Fabrication and properties of short carbon fibers reinforced copper matrix composite, J. Mater. Sci., 2008, 43(3), 974-979.

[6] Li L., Bao R., Yi J. et al., Microstructure and mechanical properties of carbon nanotube reinforced copper matrix composite prepared by microwave sintering, Mater. Sci. Eng. Powder. Metall., 2017, 22(4), 569-575.

[7] Akbarpour M.R., Alipour S., Farvizi M. et al., Mechanical, tribological and electrical properties of $\mathrm{Cu}$-CNT composites fabricated by flake powder metallurgy method, Arch. Civ. Mech. Eng., 2019, 19(3), 694-706.

[8] Yang Y.L., Wang Y.D., Ren Y. et al., Single-walled carbon nanotubereinforced copper composite coatings prepared by electrodeposition under ultrasonic field, Mater. Lett., 2008, 62(1), 47-50.

[9] Flahaut E., Peigney A., Laurent C. et al., Carbon nanotube-metaloxide nanocomposite:microstructure, electrical conductivity and mechanical properties, Acta. Mater., 2000, 48(14), 3803-3812.

[10] Treacy M.M.J., Ebbesen T.W., Gibson J.M., Exceptionally high Young's modulus observed for individual carbon nanotubes, $\mathrm{Na}$ ture, 1996, 381(6584), 678-680.

[11] Wu L.L., Yang W.J., Xu J.R. et al., Wear Resistance of Graphite/Aluminium Composite that Prepared by Stirring Casting, Adv. Mater. Res., 2013, 683:333-338.

[12] Daoush W.M., Lim B.K., Mo C.B. et al., Electrical and mechanical properties of carbon nanotube reinforced copper nanocomposite fabricated by electroless deposition process, Mat. Sci. Eng. Astruct., 2009, 513(11), 247-253.

[13] Shukla A.K., Nayan N., Murty S.V.S.N. et al., Processing coppercarbon nanotube composite powders by high energy milling, Mater. Charact., 2013, 84(10), 58-66.

[14] Kim B.J., Oh S.Y., Yun H.S. et al., Synthesis of Cu-CNT Nanocomposite Powder by Ball Milling, J. Nanosci. Nanotechnol., 2009, 9(12), 7393-7397.

[15] Ma L.L., Yu Y., Huang W. et al., Synthesis of Cu20/CNTs composite by polyol method, Act. Chim. Sinica., 2005, 63(18), 1641-1645.

[16] Singhal S.K., Lal M., Kabi S.R. et al., Synthesis of Cu/CNTs nanocomposite for antimicrobial activity, Adv. Nat. Sci: Nanosci. Nanotechnol., 2012, 3(4), 45011-45010.

[17] Hu W., Zhao H.Z., Zheng Y.H. et al., CNTs/Cu composite fabricated by ball mixing and spark plasma sintering, American Institute of Physics Conference Series. AIP Publishing LLC, 2017.

[18] LöFfler R., HäFfner M., Visanescu G. et al., Optimization of plasmaenhanced chemical vapor deposition parameters for the growth of individual vertical carbon nanotubes as field emitters, Carbon, 2011, 49(13), 4197-4203.

[19] He C., Zhao N., Shi C. et al., Synthesis of binary and triple carbon nanotubes over $\mathrm{Ni} / \mathrm{Cu} / \mathrm{Al} 2 \mathrm{O} 3$ catalyst by chemical vapor deposition, Mater. Lett., 2007, 61(27), 4940-4943.

[20] Tao X.Y., Zhang X.B., Cheng J.P. et al., Thermal CVD synthesis of carbon nanotubes filled with single-crystalline $\mathrm{Cu}$ nanoneedles at tips, Diam. Relat. Mater., 2006, 15(9), 1271-1275.

[21] Kasperski A., Weibel A., Preparation-microstructure-property relationships in double-walled carbon nanotubes/alumina composite, Carbon, 2013, 53(1), 62-72.

[22] Ran M., Sun W., Liu Y. et al., Functionalization of multi-walled carbon nanotubes using water-assisted chemical vapor deposition,
J. Solid. State Chem., 2013, 197(none), 517-522.

[23] Lee K Y., Yeoh W.M., Chai S.P. et al., The role of water vapor in carbon nanotube formation via water-assisted chemical vapor deposition of methane, J. Ind. Eng. Chem., 2012, 18(4).

[24] Hu J.L., Yang C.C., Huang J.H., Vertically-aligned carbon nanotubes prepared by water-assisted chemical vapor deposition, Diam. Relat. Mater., 2008, 17(12), 2084-2088.

[25] Yang Z., Wang L., Shi Z. et al., Preparation mechanism of hierarchical layered structure of graphene/copper composite with ultrahigh tensile strength, Carbon, 2018, 127:329-339.

[26] Zhang X.H., Zhang Y., Tian B.H. et al., Graphene oxide effects on the properties of Al203-Cu/35W5 $\mathrm{Cr}$ composite, J. Mater. Sci. Technol., 2019, 37:185-199.

[27] Zhang Q., Cai C., Qin J. et al., Tunable self-discharge process of carbon nanotube based supercapacitors, Nano. Energy., 2014, 4(1), 14-22.

[28] Pulido A., Concepcion P., Boronat M. et al., Reconstruction of the carbon sp2 network in graphene oxide by low-temperature reaction with CO, J.Mater. Chem., 2011, 22(1), 51-56.

[29] Li H., Zhao N., He C. et al., Thermogravimetric analysis and TEM characterization of the oxidation and defect sites of carbon nanotubes synthesized by CVD of methane, Mat. Sci. Eng. A-Struct., 2008, 473(1), 355-359.

[30] Kong J., Zhang C.Y., Cheng X. Novel Cu-Cr alloy matrix CNT composite with enhanced thermal conductivity, Appl. Phys. A-Mater., 2013, 112(3), 631-636.

[31] Chen F.Y., Ying I.M., Wang Y.F. et al., Effects of graphene content on the microstructure and properties of copper matrix composite, Carbon, 2016, 96:836-842.

[32] Long X., Bai Y., Algarni M. et al., Study on the strengthening mechanisms of $\mathrm{Cu} / \mathrm{CNT}$ nano-composite, Mat. Sci. Eng. A-Struct., 2015, 645:347-356.

[33] Pradyumna G., Ning H., Li X. et al., Thermal Properties of Graphene-Copper-Graphene Heterogeneous Films, Nano. Lett., 2014, 14(3), 1497-1503.

[34] Nan C.W., Birringer R., Clarke D.R. et al., Effective thermal conductivity of particulate composite with interfacial thermal resistance, J. Appl. Physics., 1997, 81(10), 6692-6699.

[35] Gutiérrez G., Carlos F., Smirnov A. et al., Wear behavior of graphene/alumina composite, Ceram. Int., 2015, 41(6), 7434 7438.

[36] Lin J., Wang L., Chen G. Modification of Graphene Platelets and their Tribological Properties as a Lubricant Additive, Tribol. Let., 2011, 41(1), 209-215.

[37] Zhai W., Shi X., Wang M. et al., Grain refinement: A mechanism for graphene nanoplatelets to reduce friction and wear of Ni3Al matrix self-lubricating composite, Wear, 2014, 310(1-2), 33-40.

[38] Ali M.K.A., Hou X.J., Improving the tribological behavior of internal combustion engines via the addition of nanoparticles to engine oils, Nanotechnol. Rev., 2015, 4(4) :347-358.

[39] Jafari Y., Ghoreishi S.M., Shabani-Nooshabadi M., Polyaniline/Graphene nanocomposite coatings on copper: Electropolymerization, characterization, and evaluation of corrosion protection performance, Synthetic. Met., 2016, 217:220-230.

[40] Patrycja Z., Gwoździk M., Nitkiewicz Z. et al., Corrosion Resistance of Sinters CNT-Cu/Cu, Solid. State. Phenomena, 2015, 227:51-54.

[41] Shabani-Nooshabadi M., Mollahoseiny M., Jafari Y., Electropolymerized coatings of polyaniline on copper by using the galvanostatic method and their corrosion protection performance in $\mathrm{HCl}$ 
medium, Surf. Interface. An., 2014, 46(7), 472-479.

[42] Fu S.L., Chen X.H., Liu P. et al., Electrodeposition and Properties of Composites Consisting of Carbon Nanotubes and Copper, J. Mater. Eng. Perform., 2018, 27(10), 5511-5517.
[43] Kamboj A., Raghupathy Y., Rekha M.Y. et al., Morphology, Texture and Corrosion Behavior of Nanocrystalline Copper-Graphene Composite Coatings, JOM, 2017, 69(7), 1149-1154. 